\& Wellstood-EAsON, S. (1985) Leicester ECT trial: results in schizophrenia. British Journal of Psychiatry, 146, 177-183.

TAYLOR, P. \& FLEMINGER, J. J. (1980) ECT for schizophrenia. The Lancet, $i, 1380-1382$.

NIMH CONSENSUS CONFERENCE (1985) Electroconvulsive therapy Journal of the American Medical Association, 254, 2103-2108.

van Valkenberg, C. \& Clayton, P. J. (1985) Electroconvulsive therapy and schizophrenia. Biological Psychiatry, 20, 699-700.

\section{Panic Attacks and Hyperventilation}

SIR: Snaith (Journal, November 1986, 149, 794) takes issue with Gelder's suggestion (Journal, September $1986,149,346-352$ ) that lowering of arterial $\mathrm{pCO}_{2}$ may be a contributory factor in the development of a panic attack, and cites four pieces of evidence that fail to support such a view. However, Snaith has misrepresented Gelder, who did not state that hyperventilation per se causes panic. The psychological model proposed by Gelder is that hyperventilation induces panic only when the bodily sensations which it induces are (a) perceived as unpleasant, and (b) interpreted in a catastrophic fashion (Clark, 1986). In this respect hyperventilation is but one of a number of various pharmacological and physiological agents (such as caffeine, yohimbine, and $\mathrm{CO}_{2}$ inhalation) which have been shown to provoke panic in susceptible individuals (Margraf et al, 1986). Thus the "overwhelming fear of dying or of becoming insane", which Snaith regards as the pathognomonic feature of a panic attack, is simply (in the cognitive model) a consequence of the misattribution of hyperventilationinduced somatic sensations to a life-threatening illness. Ley (1985) provided support for this view when he found that panic patients frequently report that the first thing they notice during an episode of anxiety is a physical feeling, most commonly breathlessness.

It is important to note that hyperventilation is neither a necessary nor sufficient prerequisite for panic anxiety. However, it is important to identify the sub-group in whom it may be a necessary condition, i.e. those in whom the symptoms of hyperventilation lead to panic, for the following reasons: firstly, the symptoms which cause panic can usually be reproduced by asking the patient to overbreathe; and secondly, the patients' fears and beliefs about the symptoms can be modified using a therapeutic technique that has been shown to be effective in reducing panic attack frequency (Salkovskis et al, 1986). We therefore need to know how this sub-group differs from those patients in whom hyperventilation does not play a role in panic.

Snaith remarks that not all patients who hyperventilate become anxious. This is certainly the case, as we have shown, but such a finding is not unexpected, since it is known that correlation between measures of physiological arousal and subjective reports of anxiety is not robust. It is also consistent with the cognitive model of anxiety. Although it has not been demonstrated that non-anxious hyperventilators do not report anxiety precisely because they do not appraise their somatic symptoms as frightening, this proposition is testable.

Snaith also points out that the administration of $\mathrm{CO}_{2}$ to patients induces anxiety rather than the reverse, and argues that such a finding is not consistent with the hyperventilation theory. But whether $\mathrm{CO}_{2}$ inhalations are anxiolytic or anxiogenic depends on the individual's cognitive set, i.e. on the instructions that are given before the inhalation. This observation emphasises the importance of cognitive factors in determining the affective state produced by manipulation of $\mathrm{CO}_{2}$ (Clark, 1986).

I agree with Snaith that there is a lack of consensus about the definition of panic. It is not clear whether panic is quantitatively or qualitatively distinct from other forms of morbid anxiety, and the word has been used to describe both a psychological and a physiological experience. Some authors have introduced additional behavioural criteria such as fear of death, fear of losing control, fear of going crazy, or an urgent need to run, in addition to DSM-III symptoms.

It should be noted that the 'hyperventilation theory' has gained ground not because of the ideology of those committed to a psychogenic rather than a biogenic explanatory model, but because of studies that have revealed the importance of not only cognitive processes, but also specific physiological abnormalities such as hypocapnia in patients with anxiety disorders (Bass, 1985). Laboratory studies using phobic imagery and other provocations may help to further clarify the relationships among cognitive, physiological, and behavioural variables in patients with panic anxiety. Finally, it is worth recalling that the impetus for splitting panic disorder from the body of anxiety disorders arose from the observation that tricyclic drugs had a specific antipanic effect. The evidence for this 'biogenic' theory of panic is not compelling (Margraf et al, 1986).

CHRISTOPHER BASS

Academic Department of Psychological Medicine

King's College Hospital

London SE5

\section{Reforences}

Bass, C. (1985) Physical symptoms of anxiety. British Journal of Clinical Practice, 39 (Suppl. 38), 34-38.

Clark, D. M. (1986) A cognitive approach to panic. Behaviour Research and Therapy, 24, 461-470.

LEY, R. (1985) Agoraphobia, the panic attack, and the hyperventilation syndrome. Behaviour Research and Therapy, 23, 79-81. 
MARGRAF, J., Ehlers, A. \& Roth, W. (1986) Biological models of panic disorder and agoraphobia-a review. Behaviour Research and Therapy, 24, 553-567.

SAlkovskis, P. M., Jones, D. R. \& ClaRk, D. M. (1986) Respiratory control in the treatment of panic attacks: replication and extension with concurrent measurement of behaviour and $\mathrm{pCO}_{2}$. British Journal of Psychiatry, 148, 526-532.

SIR: I am grateful for the opportunity to respond to the letters from Snaith (Journal, November 1986, 149, 794) and Bourne (Journal, February 1986, 150, 265-266) about my article on panic attack. In his letter in the December issue, Snaith argues that panic attacks are not caused by hyperventilation, and implies that I take the opposite view. He has misunderstood my position, for I did not conclude that hyperventilation is the most important cause of panic. The misunderstanding centres round two statements in Snaith's letter and these require a response.

Firstly, Snaith writes that the effect of cognitive treatment "supposedly supports the argument that lowering arterial $\mathrm{CO}_{2}$ is an essential component in the development of a panic attack". This is not the case: the effects of cognitive therapy support a different argument, namely that patients who experience panic attacks have a particular tendency to misinterpret bodily sensations, ascribing them to causes that are more serious than the real ones. For example, palpitations may be interpreted as evidence of heart disease. This view of panic attacks is consistent with the idea that on some occasions the misinterpreted sensations have been produced by hyperventilation, but it is not suggested that they always arise in this way. Equally, the cognitive hypothesis does not suggest that all those who hyperventilate will experience panic-only those people who have the particular tendency to misinterpret bodily sensations.

Secondly, Snaith writes that "the evidence points to the conclusion that raising, not lowering, arterial $\mathrm{CO}_{2}$ induces anxiety". In fact, raising as well as lowering $\mathrm{CO}_{2}$ can induce anxiety in some people (Van den Hout \& Griez, 1984). At first this finding seems paradoxical, but it is easily explained by the cognitive hypothesis. Thus, either an increase or a decrease in $\mathrm{pCO}_{2}$ can-through different mechanisms-cause unpleasant bodily sensations, and people who misinterpret these bodily sensations will be made anxious by either kind of change.

Returning to my own article, I did not single out hyperventilation as a frequent or major cause of panic attacks. Indeed, I concluded that it is unlikely that all panic attacks will turn out to have a single cause. I also suggested that 'biological' factors (including hyperventilation) have been overemphasised in the recent literature, and that more attention should be given to the investigation of psychological factors in these patients.

Bourne criticises me for failing to give a fuller account of Freud's views. However, he writes as though the subject of my paper were the aetiology of anxiety neurosis; in fact, it was the more specific problem of why some patients with anxiety neurosis develop panic attacks while others do not. My selective quotation from Freud was chosen to show how carefully he had described the clinical phenomena of anxiety disorders including panic attacks. I included this quotation because I agree with Bourne that some of Freud's early papers contain penetrating observations about clinical phenomena. I also agree that these observations are of great interest to present day practitioners of cognitive therapy. It is in their interpretation of the phenomena that analysts and cognitive therapists differ and, more importantly, in the kind of treatment that they have developed. Time will decide which approach is more fruitful: cognitive treatment for panic disorder is now being tested in controlled trials, but we still await reports of a comparable evaluation in which psychoanalytic treatment is compared with other methods.

M. G. GELDER

\section{University Department of Psychiatry}

Warneford Hospital, Oxford

\section{Reference}

Van den Hout, M. A. \& Griez, E. (1984) Panic symptoms after inhalation of carbon dioxide. British Journal of Psychiatry, 144, 503-507.

\section{Use of Paraldehyde}

SIR: The generally unfavourable discussion on the modern use of paraldehyde by Linter \& Linter (Journal, November 1986, 149, 650-651) cannot go unchallenged. The patient reportedly received $40 \mathrm{ml}$ of paraldehyde intramuscularly over 12 hours. This is more than double the recommended maximum i.m. dose of $30 \mathrm{ml}$ per 24 hour period (McEvoy \& McQuarrie, 1986). Paraldehyde is a drug with a disagreeable smell and special storage requirements, but over 100 years of anecdotally safe use is precisely why "Its current use is limited to psychiatric units, particularly those without resident medical cover" (Linter \& Linter, 1986): an important factor in those parts of the world that are short of doctors. Intermittent claims that paraldehyde is outmoded usually include a pharmacologically erroneous comparison with modern sedative/anxiolytics such as the benzodiazepines and phenothiazines and their derivatives. Paraldehyde belongs to the class of drugs 